\title{
The Role of Extension as a Profession Is Critical in Delivering Excellent Services: An Experience From Limpopo, South Africa
}

\author{
E. M. Zwane ${ }^{1}$ \\ ${ }^{1}$ Limpopo Department of Agriculture, Polokwane, South Africa \\ Correspondence: E. M. Zwane, Limpopo Department of Agriculture, 69 Biccard Street, Polokwane, 0700, South \\ Africa. E-mail: zwanefrank@gmail.com
}

Received: June 25, 2014 Accepted: July 27, 2014 Online Published: October 15, 2014

doi:10.5539/jas.v6n11p1 URL: http://dx.doi.org/10.5539/jas.v6n11p1

\begin{abstract}
The paper argues that professionalism also affect agricultural extension in service delivery by creating demotivated cadres in agriculture. It also provides clarification of the concept of professionalism. It draws data from researchers who did extensive work in the area of professionalism and the registration of profession, the paper seeks to achieve the following: 1) provide concrete principles of professionalism, 2) identify critical obstacles associated with professionalism, 3) review progress on efforts done to date in South Africa about professionalism in extension, 4) and highlight the qualities extensionists are expected to possess. Only three districts in Limpopo namely Capricorn, Vhembe and Sekhukhune participated in a sample of 30 extension officers. They were interviewed on their opinions about skills requirements of extension profession.

The sample was analyzed through Staistical Package for Social Science (SPSS) programme. The results revealed that certain skills are important to be possessed by the extension practitioners as seen by its rating: public speaking $86 \%$, writing $72 \%$, listening $69 \%$, research linkages $83 \%$, leadership, $76.6 \%$, critical thinking $63 \%$, supervisory $70 \%$ and communication planning $83.3 \%$. But when respondents were asked to judge themselves on the functionality of those skills, it was found wanting. The paper concludes with some recommendations.
\end{abstract}

Keywords: profession, professionalism, excellent services, Limpopo, South Africa

\section{Introduction}

The debate about the concept of professionalism in Agriculture is not new. Its relevancy, justification, promotion as well as its meaning has been a burning concern among academics, extension practitioners and policy makers and the public to some extent which questions the visibility and the image thereof. Academics responded by conducting research and presented papers in conferences (Terblanche, 2007; Jibowo, 2007; Koch \& Terblanche, 2013; Lukhalo, 2013). Extension practitioners on the other hand were vocal through their agricultural societies who developed proposals and took part in research to come up with research to justify the need for opening up for agricultural extension science profession. The policy makers represented by the Department of Agriculture Forestry and Fisheries (DAFF) and Provincial leadership have provided an enabling environment for holding and pursuing a position to address the foregoing concerns. It should be mentioned that these parties who showed their willingness to cooperate have made it possible for the South African Council for Natural Scientific Professions to recognize Agricultural Extension as one of the field of practice within the South African context of the natural scientific professions act of 2003. The objective of this paper is fourfold: 1) to provide concrete principles of professionalism, 2) to identify critical obstacles and solutions linked to professionalism, 3) review progress on efforts done to date in South Africa about professionalism in extension, 4) and to discuss the findings of the research on what could be the most important roles of the extension as a profession.

\section{Theoretical Background}

The journey towards professionalism in South Africa was championed by not a single person but a collective each one doing a part in the process. The South African Society for Agricultural Extension (SASAE) made some efforts by participating in the Standard Generating Body (SGB) (Enslin, 2006) and it further developed an extension landscape which categorize its members towards professionalism (De Beer, 2005). The land scape became a foundation of the categorization of the membership as seen in the new document outlining the registration of practitioners. In 2007, SASAE reminded its members when it featured "professionalism" as a 
theme in one of its annual Extension Conference. Other role players such as DAFF expressed the need for professionalization of Extension and Advisory Services (Norms \& Standards, 2005).

However the critical time was reached when DAFF commissioned a feasibility study on the establishment of a professional South African Extension and Advisory body. South Africa is one of the model country in Africa considered to have the potential to influence development in Africa. But when it comes to Agricultural Extension it has lagged behind partly because it did not have an extension policy. According to Lukhalo (2013), the policy process got underway during 2012 and it can be argued that lack of an operational agricultural extension policy in South Africa, has delayed the recognition of extension as a profession. The existence of such a policy could have created a quick enabling environment to professionalize extension service. However it should be indicated that the establishment of the Extension Recovery Plan (ERP) in 2008 has influenced the process of professionalization of extension. A profession is determined by a number of traits.

Goode (1960) identified ten traits which are still relevant today as confirmed by (Wikipedia, 2014; Duvel, 2007). They are: 1) the profession determines its own standards of education and training, 2) the student profession goes through a more far-reaching adult socialization experience than the learner in other occupations, 3 ) professional practice is often legally recognized by some form of licensure, 4) Licensing and admission boards are manned by members of the profession, 5) most legislation concerned with the profession is shaped by that profession, 6) the occupation gains in income, power, and prestige, ranking, and can demand higher caliber students, 7) the practitioner is relatively free of lay evaluation and control, 8) the norms of practice enforced by the practice are more stringent than legal control, 9) members are more strongly identified and affiliated with the profession than are members of other occupations with theirs. 10) The profession is more likely to be a terminal occupation.

\section{Research Methods}

This study formed part of a larger study conducted by a team of extension experts in the Southern African Development Community (SADC) region. It was the arrangements that each country will conduct individual study. The author was responsible for South Africa, however due to the size of the country and other logistical issues such as time and budget arrangements and such as budget and time, data was collected from only three (3) districts of the five (5) identified districts in the province. The study area consisted of Capricorn, Sekhukhune and Vhembe.

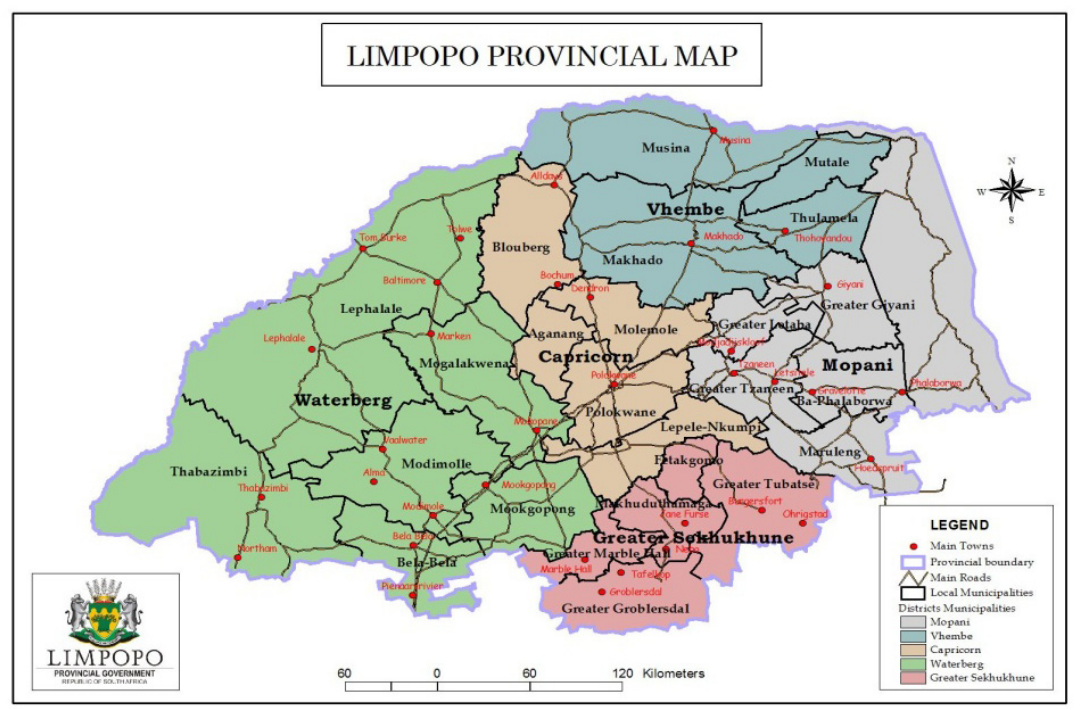

Figure 1. Limpopo map

The purposively selected districts which formed the sample are indicated in Table 1, namely Capricorn (12), Sekhukhune (9) and Vhembe (9). 
Table 1. Sample size

\begin{tabular}{ccc}
\hline Name of district & Number of respondents & Percentage \\
\hline Capricorn & 12 & 40 \\
Sekhukhune & 9 & 30 \\
Vhembe & 9 & 30 \\
Total & 30 & 100 \\
\hline
\end{tabular}

A total of thirty extension workers participated in the study. Although the purposively selected sample size of 30 might not be representative of the extension population in Limpopo Province and also, while this makes the findings not to be generalizable to the province (Dillman et al., 2009), the results are still very much relevant and worth reporting as they address issues of importance in agricultural extension.

\section{Results and Discussion}

The overall purpose of the study reported here was to identify and prioritize the professional development needs of Extension in the three districts of Limpopo.

\subsection{Objective 1: Demography of the Respondents}

The study presents results which are divided into demography, gender, and the requirement of professionalism. This was one of the objective of the study to establish the demographic profile of the extensionists.

\subsubsection{Gender}

The majority of the respondents were male constituting 70 percent and 30 percent female. This is not surprising because a study conducted in Limpopo Provinces of South Africa display a similar tendency (Zwane, 2009). This could be seen as a legacy of colonialism and apartheid which connoted a negative image to women's roles in society.

\subsubsection{Marital Status}

The respondents were asked to indicate their marital status. The findings reveal that 76.7 percent were married, 20 percent single but not married and 3.3 percent indicated being single parents. Experience has shown that there is stability in the workforce with individuals who are married as compared to single or people co-habiting (Bembridge, 1991).

\subsection{Objective 2: Principles of Professionalism}

The word profession and professionalization, and professionalism could be used interchangeably as if they mean the same thing. In terms of Wikipedia (2014) Professionalization is the social process by which any trade or occupation transforms itself into a true profession of the highest integrity and competence. This process tends to involve establishing acceptable qualifications, a professional body or association to oversee the conduct of members of the profession and some degree of demarcation of the qualified from unqualified amateurs. Whereas professionalism refers to a wider perspective because the title has been adopted by criminals who see themselves as professionals (Terblanche, 2012).

However the term profession refers to a vocation founded upon specialized educational training. The purpose of which is to supply objective counsel and service to others (Wikipedia, 2014), Extensionists who have received the correct training see themselves as professionals. The acceptance of extension as a field of profession is opening doors for the extensionists to practice professionalism It is important to note that a profession is widely accepted to be an occupation that requires extensive training and the study and mastery of specialized knowledge, and usually has a professional association, ethical code and process of certification of licensing (Duvel, 2007).

Practicing a profession depends on the Acts, for example in Canada extension and advisory are governed by the Agrologist Act, of 1994 whereas in South Africa it is governed by Natural Scientific Professions Act (Act No. 106 of 1993) which was later replaced by Act No. 27 of 2003) (Duvel, 2007). The custodian of the Act is a body called; South African Council for Natural Scientific Professions (SACNASP). Gibson and Hillison (1994) suggest that effective extension specialists must understand the Extension education process. In addition, they must understand the human development, learning, and social interaction processes, and they must become knowledgeable about the organization within which they work and this has been supported by other researchers for example (Duvel, 1990) notes that a profession should be a job with an intellectual character and the major elements of such a profession should include: philosophy, body of knowledge, leadership, guidelines for 
behaviour, and admission requirements.

\subsection{Objective 3: Reviewing Progress on Professionalism in Extension in South Africa}

The tools and procedure used as forerunner in the process have been documented. It is sufficing to indicate that four policy documents were developed by the Department of Agriculture, Forestry and Fishery. They include: Norms and Standards in 2005, the development of Extension Recovery Plan in 2008, the feasibility study on professionalism in 2012, and the draft Extension Policy in 2012 (Lukhalo, 2014). The efforts of DAFF and its partners have led to SACNASP agreeing to accommodate Agricultural Extension Science as a field of practice in South Africa (Bekker, 2013).

South African Council for Natural Scientific Professions (SACNASP) and South African Society of Agricultural Extension (SASAE) have played a major role in the process. What need to be worked out is the logistics of registration by extension practitioners. There are criteria developed for this purpose. They are; Professional Extension Scientist (Pr. Ext. Sc.), Candidate Extension Scientist (Cand. Ext. Sc.), Extension Technologist (Ext. Techn.); Candidate Extension Technologist (Cand. Ext. Techn.); Associate Extension Technician (Assoc. Ext. Tech.); The criteria to determine a registration category is based on the number of extension credits earned at a certain level of study (e.g. a Masters qualification with a minimum of 120 credits in extension) and the years of appropriate working experience in extension (Beker, 2013).

\subsection{Objective 4: Critical Obstacles Associated With Extension Profession}

Any profession faces challenges and obstacles. One of the critical factors is the size of the participating professionals. It has been acknowledged that the number of extension officers are insufficient in South Africa for example South Africa has a total number of 2200 (Terblanche, 2012), however, this number was increased by the provisions made in the Extension Recovery Members of a profession may encounter conflict when working with personnel from other professions. It is a group of professionals each with his own training, professional societies, and code of ethics (Duvel, 2007). Another observation is that the attitude of a professional determines his productivity.

A professional who has been trained by an organization tend to be loyal to the organization and may receive more reward compared with a professional who came outside the organization, who may not look to his boss for approval but to his peers (Hurd, 1967). It has been noted by researchers that shortage of trained and experienced agricultural extensionists in South Africa has been the subject of much debate in recent years (Terblanche, Koch, $\&$ Lukhalo, 2012). Some of the challenges that are the impediments in professionalism in extension have been documented which include inadequate specialization in Extension, inadequate financial backing, inadequate research culture, low impact, and competition by other disciplines in the field of agriculture (Jibowo, 2007).

\subsection{Objectives 5: Professional Requirements of Extension}

\subsubsection{Public Speaking}

It has been asserted that Agricultural Extension has made limited impact in many countries in bringing about production of food surplus in a sustainable manner (Jibowo, 2007). The study revealed that extension practitioners rated public speaking $86 \%$. This is not surprising because specialists need to develop skills in documenting program impact and also in communicating that impact to their stakeholders. This view was supported in a different survey conducted by Clemson University (Radhakrishna, 2001).

\subsubsection{Writing Skill}

Extension specialists have the responsibility to synthesize, evaluate, integrate, and apply research information. The study found that this criterion was rated $72 \%$. This skill is indeed very important for the specialists because they need to apply the information. (Taylor \& Summerhill, 1994) found that expertise from within the land-grant university system was performing this task in support of county programming efforts.

\subsubsection{Listening Skills}

This criterion was rated $70 \%$ to indicate its importance. Several studies reveal that Extension specialists are one of the primary sources of information for county agents (Radhakrishna \& Thompson, 2001).

\subsubsection{Communication Planning}

According to Van den Ban (1990), applying relevant skills should be seen as communication in agriculture, this has improved the returns on investment. The study has rated this criteria $83.3 \%$ and this has been supported by to be important because of this belief that agricultural extension involves dissemination of improved knowledge to farmers and assisting them to apply (Jibowo, 2007). 


\subsubsection{Leadership}

Terblance (2007) indicated that extension specialist needs to be able to manage. Coupled with management is leadership. This criteria was rated $76.6 \%$. The importance of this quality has been confirmed by Radhakrishna (2001) who noted that Specialists are key individuals in providing the technical information that drives county Extension programming.

\subsubsection{Critical Thinking}

The study found that this criterion was rated $63 \%$ Extension specialists perceive this criteria to be very important hence it was rated above $50 \%$. The reason is because they perceived a specialist to possess a high level of competence in critical thinking. Nearly half of the professional development needs examined in this study. This finding was confirmed by Radhakrishna (2001).

\subsubsection{Research Linkages}

Hagman (1999) observed that the traditional approach to liking research with farmers has been strongly criticized due to its linear approach. This criterion has been rated $83 \%$. This is a high percentage which acknowledge its importance. This view has been carried by many traditional researcher who held the view of its importance for a wrong reason, for example Radhakrishna (2001) agreed that extension specialists need to step up their efforts to communicate client problems to researchers so that appropriate Extension programs and/or solutions can be offered.

\subsubsection{Supervision Skills}

Mathabatha and Duvel (2005) found that supervision has played a role in ensuring that the relationship between the subordinates and the leadership remain positive. However where the subordinates were asked to rate their supervisors it was not satisfactory. Whereas when the supervisors were asked to rate themselves they all rated above $70 \%$. The study found that this criterion was rated $73 \%$. This is an opinion of the subordinates. It still sends a strong message that supervision is important for the specialists.

\subsubsection{Group Facilitation}

Duvel (2007) identified the important skills which he felt are very important for a professional extensionist to have namely management, supervision and group facilitation. The study found that this criteria was rated $70 \%$. This shows the seriousness of this skill.

\section{Conclusion and Recommendations}

In conclusion it should be stated that professionalizing extension and advisory practitioners in South Africa should be considered highly by all stake holders interested in agricultural development. It is the writer's view that the absence of a professionalized extension science, has caused much damage to the dignity of the extension and advisory practitioners. The reason is that some of the extension practitioners got demotivated. The impact of the damage is that some of the extension practitioners have become demotivated and therefore are compromising service delivery. Professionalization of agricultural extension was not an easy one. We can bear witness that this has been the product of different stake holders working together for a common cause.

The paper has succeeded in highlighting the achievement of its objective. Of critical significance is the fact that respondents have confirmed the 9 qualities as critically important to be possessed and practiced by all professionals. All these qualities were rated above $60 \%$, which further demonstrate how important these criteria are to be possessed by extension practitioners. The finalization of the agricultural extension to be part of the profession within the confines of the South African Council for Natural Scientific Professions requires that efforts be taken consciously to deal with the challenges of poor service delivery. For this reason few recommendations are made in 5.1.

\subsection{Recommendation}

As indicated that a profession consist of disciplinary procedures and the philosophy, it is recommended that:

- The parties involved should come up with a set of rules to handle, monitor and manage the profession in a professional manner.

- An action plan needs to be developed in order to bring or maintain a variety of competences among the extension practitioners, who should strive for excellence in order to improve service delivery.

- Extension practitioners need to be encouraged to conduct extension research.

- A code of ethics should be made known to all members. 
- $\quad$ That the Department of Agriculture Forestry and Fisheries (DAFF) should facilitate capacity building through seminars to the serving personnel as a way to instil a sense of accountability to the profession.

- The members of the profession should always be reminded of the code of ethics of the agricultural extension profession.

\section{References}

Becker, R. (2013). Registration with the South African Council for Natural Scientific Professions. Presentation to the South African Society for Agricultural Extension, University of the Free State.

Bembridge, T. J. (1991) The Practice of Agricultural Extension. A Training Manual. Development Bank of Southern Africa, Half way House, Midrand.

De Beer, L. (2005). Extension Landscape in South Africa. South African Society for Agricultural Extension.

Dillman, D. A., Smyth, J. D., \& Christian, L. M. (2009). Internet, Mail and Mixed Mail Surveys. The Tailored Designed Method. New Jersey: John Wiley \& Sons.

Duvel, G. (2007). Professionalism in Agricultural Extension: justification and challenges for extension in south Africa. Proceedings of 41 SASAE Conference. 8-10 May, Golden Horse Casino Hotel, Pietermaritzburg.

DüveL, G. H. (1990). Projected demands on extension- a professional extension approach. Proceedings of 24th SASAE Conference. 24-26 April, 1990, Port Elizabeth.

Enslin, B. (2006). Extension landscaping. Standard Generating Body. Primary Agriculture Education and Training Authority (PAETA), Impetus Consulting. Pretoria.

Gibson, J., \& Hillison, J. (1994). Training needs of area specialized extension agents. Journal of Extension, 32(3). Retrieved from http://www.joe.org/joe/1994october/a3.html

Goode, W. J. (1960). Encroachment, Charlatanism, and the Emerging Profession: Psychology, sociology and Medicine. American Sociological Review XXV 903. Reprinted by the permission of the American Sociological Association.

Hagmann, J. (1999). Learning together for change. Facilitating innovation in natural resource management through learning process approaches in rural livelihoods in Zimbabwe. Margraf Verslag. Weikerheim. Germany.

Hurd, H. G. (1967). What is a professional. University College, Rutgers, The State University. New Brunswick. New Jersey.

Jibowo, A. A. (2007). Reauisites for professionalism in Agricultural Extension. Obstaacles to and Reauisite for Professionalism in Extension. Paper presented in Extension Conference of SASAE held in Pietermaritzburg.

Lukhalo. T. (2013). Overview of the Draft National Policv on Extension and advisorv services National Consultation Meeting with Provinces. Department of Agriculture, Forestry and Fisheries, Pretoria.

Lukhalo, T. (2014). Registration of Extension Profession. Presentation made in Limpopo Extension and Advisory Conference, Bolivia, Polokwane.

Mathabatha, M. C., \& Duvel, G. (2005). Supervisory skills of extension managers in Sekhukhune district of Limpopo Province. Paper presented in SASAE Conference. 9-12 May, 2005. Bloemfontein.

Norms and Standard. (2005). Department of Agriculture Forestry and Fisheries. Pretoria.

Radhakrishna, R. B. (2001). Professional Development Needs of State Extension Specialists. Journal of Extension, 32(3). Retrieved from http://www.joe.org/joe/2001ctober/a3.html

Radhakrishna, R. B., \& Thomson, J. S. (1996). Extension agent's use of information sources. Journal of Extension, 34(1). Retrieved from http://www.joe.org/joe/1996february/rb2.html

Taylor, C. L., \& Summerhill, W. R. (1994). Concept of state major programs and design teams. Fact Sheet PE-56. Florida Cooperative Extension Service. IFAS. University of Florida, Gainesville, FL.

Terblanche, S. E. (2007). Towards professionalism in agricultural extension: The professional registration of Extensionists in South Africa - A dream or a reality? The role of the South African Society of Extensionists in South Africa - A dream or a reality? South African Journal of Agricultural Extension, 36(1), 144-169.

Terblanche, S. E., Koch, B. H., \& Lukhalo, T. (2012). The Feasibility of Establishing a professional South African Extension and Advisory Body. DAFF, Pretoria 
Van Den Ban, A. W., \& Hawkins, H. S. (1990). Agricultural extension. Second Edition Blackwell Science Ltd. Oxford.

Wikipedia. (2014). Retrieved from http://en.wikipedia.org/wiki/Professions

Zwane, E. M. (2009). Participatory development of an extension approach and policy for Limpopo Province, South Africa. PhD Thesis, University of Pretoria.

\section{Copyrights}

Copyright for this article is retained by the author(s), with first publication rights granted to the journal.

This is an open-access article distributed under the terms and conditions of the Creative Commons Attribution license (http://creativecommons.org/licenses/by/3.0/). 